\title{
Factors associated with positive and negative recommendations for cancer and non-cancer drugs for rare diseases in Canada
}

Fernanda Naomi Inagaki Nagase ${ }^{1 *}$ (D, Tania Stafinski ${ }^{1}$, Jian Sun ${ }^{1,2}$, Gian Jhangri ${ }^{3}$ and Devidas Menon ${ }^{1}$

\begin{abstract}
Background: In Canada, reimbursement recommendations on drugs for common and rare diseases are overseen by the Canadian Agency for Drugs and Technologies in Health (CADTH) and made through the pan-Canadian Oncology Drug Review (pCODR) and the Common Drug Review (CDR). While the agency specifies information requirements for the review of drug submissions, how that information is used by each process to formulate final reimbursement recommendations, particularly on drugs for rare diseases (DRDs) in which per patient treatment costs are often high, is unclear. The purpose of this study was to determine which factors contribute to recommendation type for DRDs.
\end{abstract}

Methods: Information was extracted from CDR and pCODR recommendations on drugs for diseases with a prevalence < 1 in 2000 from January 2012 to April 2018. Data were tabulated and multiple logistic regression was applied to explore the association between recommendation type and the following factors: condition/review process (cancer vs non-cancer), year, prevalence, clinical effectiveness (improvements in surrogate, clinical and patient reported outcomes), safety, quality of evidence (availability of comparative data, consistency between population in trial and indication, and bias), clinical need, treatment cost, and incremental cost-effective ratio (ICER). Two-way interactions were also explored.

Results: A total of 103 recommendations were included. Eleven were resubmissions, all of which received a positive recommendation. Among new submissions $(n=92)$, DRDs that were safe or offered improvements in clinical or patient reported outcomes were more likely to receive positive reimbursement recommendations. No associations between recommendation type and daily treatment cost, cost-effectiveness, or condition (cancer or non-cancer) were found.

Conclusions: Clinical effectiveness, as opposed to economic considerations or whether the drug is indicated for cancer or non-cancer, determine the type of reimbursement recommendation.

Keywords: Rare diseases, Orphan drugs, Reimbursement review

\footnotetext{
* Correspondence: fnagase@ualberta.ca

${ }^{1}$ Health Technology \& Policy Unit, School of Public Health, University of

Alberta, Edmonton, AB, Canada

Full list of author information is available at the end of the article
}

(c) The Author(s). 2019 Open Access This article is distributed under the terms of the Creative Commons Attribution 4.0 International License (http://creativecommons.org/licenses/by/4.0/), which permits unrestricted use, distribution, and reproduction in any medium, provided you give appropriate credit to the original author(s) and the source, provide a link to the Creative Commons license, and indicate if changes were made. The Creative Commons Public Domain Dedication waiver (http://creativecommons.org/publicdomain/zero/1.0/) applies to the data made available in this article, unless otherwise stated. 


\section{Background}

Coverage decision-making on new drugs for rare diseases (DRDs) challenges public and private payers, as well as the pharmaceutical industry in Canada and abroad. In addition to high per patient treatment costs, DRDs typically come with a paucity of outcomes data due in part to the small number of patients available for studies. This creates significant uncertainty around their value proposition. At the same time, DRDs often target diseases with high clinical need (i.e., they are lifethreatening and/or chronically debilitating and lack active treatment/disease-modifying alternatives) $[1,2]$.

In Canada (unlike other countries), participating public payers rely on one of two centralised review processes (depending on disease type) to provide coverage recommendations on new DRDs. Prior to 2003, recommendations were made by individual jurisdictions (e.g., provinces and territories) through separate provincial/territorial processes or, in the case of cancer drugs, jurisdictional cancer agencies. In 2003, the centralized Common Drug Review (CDR) was launched as a means of improving the efficiency of such processes and providing high quality evidence-informed recommendations on non-cancer drugs to guide coverage decisions in all participating jurisdictional drug plans. In 2011, a parallel process, the pan-Canadian Oncology Drug Review (pCODR), was established for new cancer drugs. Both of these centralized processes are overseen by the Canadian Agency for Drugs and Technologies in Health (CADTH) [3, 4]. Although CADTH broadly specifies factors considered when formulating recommendations (clinical benefit, cost, cost-effectiveness, and patient preferences), how they are weighed relative to one another and whether it varies under certain conditions remain unclear [5].

In recent years, several analyses of centralized drug review processes have been published [6-12]. While most have focused on drugs for common conditions, three have assessed trends and factors associated with different types of coverage recommendations for DRDs. However, these studies excluded cancer drugs and examined only a small number of decision factors $[6,7,9]$.

This study aimed to address the following questions:

1. Are certain factors associated with positive or negative reimbursement recommendations for drugs submitted to CDR and pCODR?

2. Does whether or not the DRD is for a cancer indication affect recommendation type?

\section{Methods}

A quantitative analysis was conducted to address these questions. The identification and extraction of data from CDR and pCODR submissions followed guidelines for conducting systematic reviews [13].

\section{Identification of DRDs}

All DRD recommendations from CDR and pCODR from January 2012 until April 2018 were included in the study. Before 2011, submissions for cancer drugs were reviewed by the interim Joint Oncology Drug Review (iJODR) and information on recommendations was not made publicly available. After 2011, the iJODR was formalized to a permanent body known as pCODR managed by CADTH and the first recommendation was published in 2012. Also, previous studies have shown differences in factors associated with CDR recommendations before and after the establishment of pCODR (i.e. 2012, [7, 9]. Therefore, to make recommendations comparable, CDR submissions prior to 2012 were excluded from the analyses. A rare disease was defined as a condition affecting less than 1 in 2000 people in Canada (the definition proposed in the draft pan-Canadian framework for rare diseases which had been developed by Health Canada, the national regulating body [14]). Ultrarare diseases were defined as those with a prevalence of less than 1 in 50,000 people [15]. To identify DRDs, prevalence information was obtained from two sources: 1) the Orphanet website, an internationally governed portal for rare disease information containing a comprehensive list of rare diseases [16], and 2) a comprehensive search of published and grey literature for Canadian prevalence estimates (details of the search strategy are available from the authors).

\section{Collection of data on included DRDs}

For each included DRD, the CDR and pCODR "Final Recommendation" documents were obtained from their respective websites [3, 4]. These documents are issued by CADTH once a reimbursement recommendation is made by an independent review committee and provide the reasons for the recommendation, considering: current available evidence on safety and clinical effectiveness, cost-effectiveness, patient input, characteristics of the drug and disease, and feasibility of adoption of the current technology (e.g. budget impact analysis and organization feasibility) $[3,4]$.

\section{Data extraction}

For each included DRD, two researchers independently reviewed the relevant "Final Recommendation" document and extracted the following information using a standardized form [13]: submission type, drug name, drug type, condition/indication, final recommendation, year of final recommendation, number of randomized clinical trials (RCTs), number of patients from studies, clinical safety and efficacy/effectiveness, quality of evidence (e.g. presence of bias in outcome measures, availability of comparative data), treatment cost, and cost-effectiveness. 


\section{Data analysis \\ Creation of variables}

For each included DRD, the final recommendation was converted into a binary outcome variable coded as positive if the recommendation was to 'list' the drug (i.e., include it in a participating publicly funded drug benefit plan) with or without conditions and negative if the recommendation was to not 'list' the drug. Factors were converted to categorical variables characterizing the submissions, including the type of submission (new or resubmission), prevalence of the condition (orphan or ultra-orphan) and type of drug (alimentary tract/metabolism product, antineoplastic/immunomodulating agent or other) were created. Four binary variables ('yes' or 'no/ not measured') were created to describe the presence or absence of meaningful improvements across efficacy and effectiveness outcomes: 1) differences in clinical outcomes, 2) differences in biomarker/surrogate outcomes, and 3) differences in patient reported outcomes (PROs). Classification of the outcomes was based on the definitions described in the "Final recommendation" documents. The following binary ('yes' or 'no') variables were also created: safety issues, bias in outcome measures, consistency between the patient population in trials and indication(s) for which a reimbursement/listing recommendation was sought, availability of direct comparative data, availability of long-term data, and presence of other methodological or study design issues. A detailed description of these variables is provided in Table 1.

\section{Statistical analysis}

First, a series of two-by-two or three-by-two tables were constructed to examine the percentage of positive recommendations for each variable extracted from the "Final recommendation" document. Data were tabulated for all included recommendations and stratified by type of condition (i.e. cancer and non-cancer) to examine whether the frequency of positive and negative recommendations for each factor (i.e., independent variable) varied with type of condition. Pearson's chi-square or Fisher's exact test were used to test the statistical significance of differences in such percentages. This step was also used to check for any errors and spot complete and quasi-complete separation of data (i.e. recommendations were almost perfectly predicted by the independent variables).

Next, factors potentially associated with recommendation type were further explored through multiple logistic regression- a statistical analysis that allows for the assessment of the association between multiple factors and a dichotomous outcome (in this case, positive or negative recommendation) [18]. Two methods for building regression models were used and the results compared: 1) purposeful selection and 2) stepwise selection.
In purposeful selection, covariates whose univariate test had a $p$-value $<0.21$ were first identified $[18,19]$. A multivariable model containing these covariates was constructed, and variables with $p$-values $>0.21$ were excluded. Each variable not selected initially for inclusion in the multivariable model was then added one at a time. If its $p$ value was $>0.05$ and none of the coefficients in the model changed by $>20 \%$, the variable was excluded. The resulting model comprised the main effects model. Finally, twoway interactions among the variables were added to the main effects model one at a time and checked for statistical significance. Those with $p$-values $>0.05$ were excluded. To assess the fit of final model, the HosmerLemeshow goodness-of-fit test was used [20, 21].

In stepwise selection, each variable was entered into the model step by step (SAS ${ }^{\odot}$ Stepwise Logistic Regression). The significance level for entry and stay were set at 0.2. The results were identical with purposeful method.

\section{Results}

Initially, 104 submissions (42 CDR and 62 pCODR) with final recommendations on DRDs were identified. Fifteen were excluded (11 resubmissions and 4 with no daily treatment cost information), leaving a total of 88 submissions comprising 92 final recommendations for inclusion in the analysis (Fig. 1). Resubmissions $(n=11)$ were excluded since they all received a positive recommendation. Of the 103 recommendations, 82 (80\%) were positive (Table 2). Most recommendations were for antineoplastic \& immunomodulating therapies, but the proportion of positive recommendations among different 'therapeutic class of drugs' were similar.

Figure 2 shows the number of recommendations on new submissions made each year since 2012. From 2012 to 2014, the average was around 9 per year, whereas after 2015, the average increased to 19 (2018 was excluded since the data were only available for the first quarter of the year). Overall, the proportion of positive recommendations on new submissions remained high (ranging from 63 to 100\%). While the proportion of positive recommendations on cancer DRDs remained similar over the years, that for non-cancer DRDs increased after 2015 (Fig. 3). However, the number of noncancer DRD submissions was also small prior to 2015.

Table 3 provides information on the distribution of positive recommendations according to each potential decision factor and stratified by cancer and non-cancer drugs. Twenty-five (96\%) out of 26 recommendations showing 'improvement in clinical outcomes' were positive. Only one in cancer reporting 'improvements in clinical outcomes' was negative. Likewise, 24 of 25 (96\%) recommendations reporting 'improvements in PROs' were positive and the proportion of positive recommendations was similar for cancer and non-cancer DRDs. 
Table 1 Description of variables included in the analyses

\begin{tabular}{ll}
\hline Variable & Values \\
\hline Recommendation & 0 if negative \\
& 1 if positive \\
Submission characteristics & \\
Year of recommendation & Continuous variable \\
Type of submission & 0 if new submission \\
Presence of RCTs & 1 if resubmission \\
& 0 if no \\
Therapeutic class of drugs & 1 if yes \\
& 0 if alimentary tract \& \\
& metabolism \\
1 if Antineoplastic \& & immunomodulating \\
& 2 if other
\end{tabular}

Details

- Negative: do not list

- Positive: list, list with conditions, list with criteria, list if price reduced or cost-effectiveness improved

- Year of final recommendation

- Type of submission according to CADTH classification

- RCTs were included in the systematic review

- Classification of drugs based on ATC codes

0 if cancer

1 if non-cancer

Type of condition

0 if ultra-orphan

1 if orphan

Prevalence

0 if no or not stated

1 if yes

0 if yes

1 if no

0 if no, inconsistent or not measured

1 if yes

- Orphan: < 1 in 2000 people
Improvements in clinical outcomes

Improvements in PRO

Quality of evidence

Availability of comparative data

0 if no

1 if yes

Consistency between population in trials and indications

Bias in outcome measures

0 if yes

1 if no

Long term data

1 if yes

0 if no
0 if no, inconsistent or not measured

1 if yes

0 if no, inconsistent or not measured

1 if yes

1 if yes

- Classification based on ICD-10

- Ultra-orphan: < 1 in 100,000 people

- Need for alternative treatment options, no existing treatment or "unmet need"

- Concerns over potential serious life-threatening adverse events or unknown safety profiles

- Biomarker is "a defined characteristic that is measured as an indicator of normal biological process, pathogenic process, or responses to an exposure or intervention, including therapeutic interventions" [17]. - Surrogate outcome is "an endpoint that is used in clinical trials as a substitute for a direct measure of how a patient feels, functions, or survives" [17].

- Meaningful improvements defined as statistically significant differences or non-inferiority in biomarker/ surrogate outcomes (e.g. weight, 6 min walk test, progression-free survival)

- Clinical outcome is "an outcome that describes or reflects how an individual feels, functions or survives" [17].

- Meaningful improvements defined as statistically significant differences or non-inferiority in clinical outcomes (e.g. survival, transplantation)

- PRO is "a measurement based on a report that comes directly from the patient about the status of a patient's health condition without amendment or interpretation of the patient's response by a clinician or anyone else" [17].

- Meaningful improvements defined as statistically significant differences or non-inferiority in PRO (e.g. QOL, rating of pain intensity, SF-36)

- Based on availability of direct head-to-head comparative studies (where comparators were available)

- Present when 'final recommendation' document stated that data from trials included all subgroup of the indicated population

- Not present when for example submitted indication includes mild, moderate, and severe forms of disease but trial data limited to mildmoderate forms of disease

- Present when indicated in the final recommendation document

- Bias in outcome measurements (e.g., subjective outcomes classified by non-blinded investigators)

- Presence of long-term data where long-term data is important given the course of disease

- Present when indicated in the final recommendation document 
Table 1 Description of variables included in the analyses (Continued)

\begin{tabular}{|c|c|c|}
\hline Variable & Values & Details \\
\hline Other study design issues & $\begin{array}{l}0 \text { if yes } \\
1 \text { if no }\end{array}$ & $\begin{array}{l}\text { - Concerns over other aspects of study design (e.g., small sample size, } \\
\text { carry-over effects associated with withdrawal trial methodology) } \\
\text { - Present when indicated in the final recommendation document }\end{array}$ \\
\hline \multicolumn{3}{|l|}{ Cost/ cost-effectiveness } \\
\hline Daily treatment cost & $\begin{array}{l}\text { Continuous variable in } \\
\$ C D N / \text { patient }\end{array}$ & - Average daily treatment cost of drugs per patient \\
\hline ICER & $\begin{array}{l}\text { Continuous variable in } \\
\$ C D N / Q A L Y\end{array}$ & $\begin{array}{l}\text { - ICER calculated by CADTH or by manufacturer if no ICER calculated by } \\
\text { CADTH was available }\end{array}$ \\
\hline
\end{tabular}

ATC Anatomical Therapeutic Chemical (ATC) Classification System, CADTH Canadian Agency for Drugs and Technologies in Health, ICD International Classification of Disease, ICER Incremental Cost-effectiveness Ratio, ICU Intensive Care Unit, PRO Patient- reported Outcome, QALY Quality-adjusted Life Years, QOL Quality of Life, RCT Randomized Controlled Trial

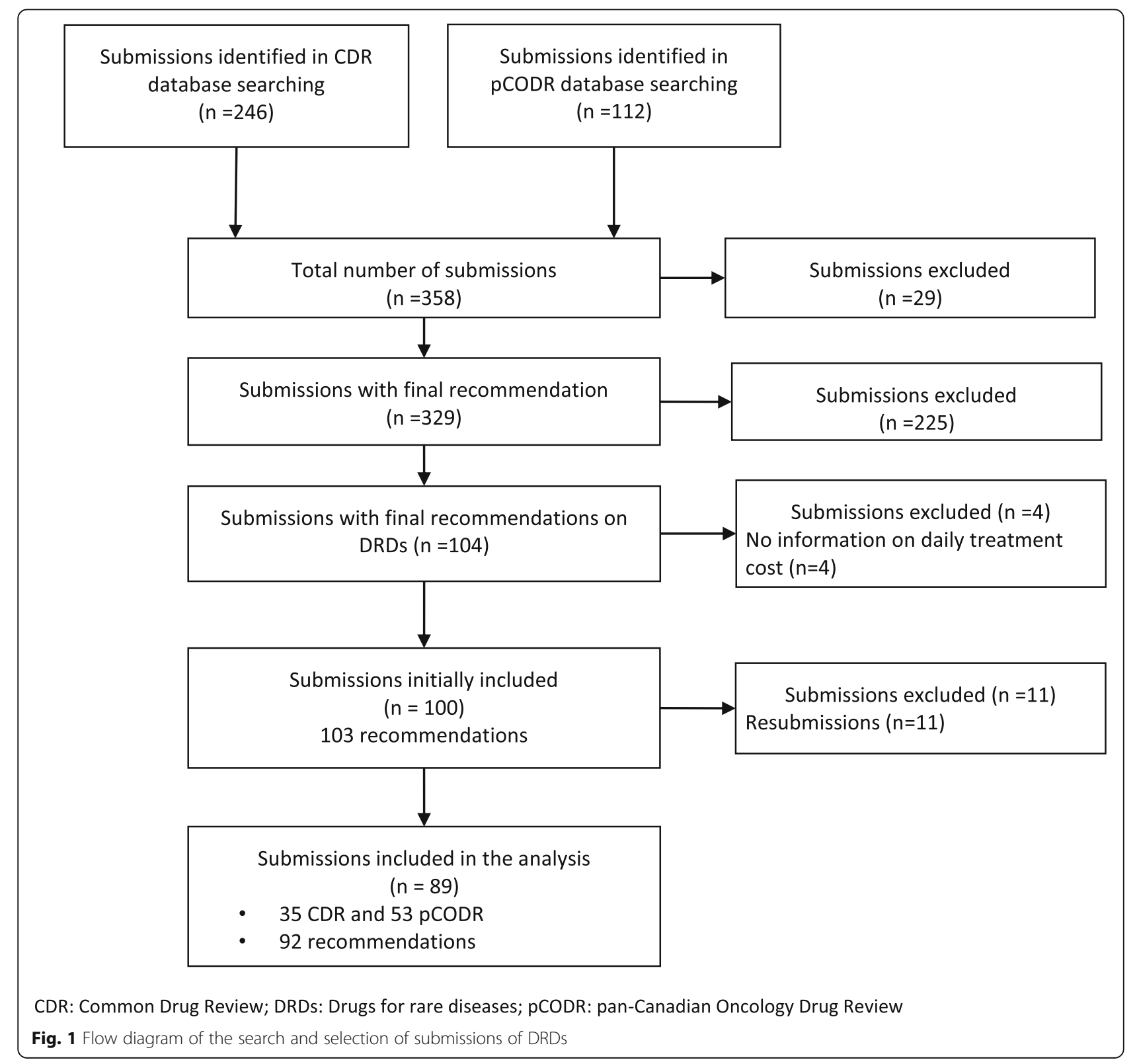


Table 2 Overall description of included recommendations

\begin{tabular}{|c|c|c|c|c|}
\hline Factors & $n$ & Positive recommendations & $\%$ Positive & $p$-value \\
\hline All & 103 & 82 & 79.6 & - \\
\hline Therapeutic class of drug & & & & 0.711 \\
\hline Alimentary tract \& metabolism & 11 & 10 & 90.9 & \\
\hline Antineoplastic \& immunomodulating & 78 & 61 & 78.2 & \\
\hline Others & 14 & 11 & 78.6 & \\
\hline Type of condition & & & & 0.879 \\
\hline Cancer & 66 & 53 & 80.3 & \\
\hline Endocrine & 16 & 12 & 75.0 & \\
\hline Others & 21 & 17 & 80.9 & \\
\hline Type of submission & & & & 0.070 \\
\hline New & 92 & 71 & 77.2 & \\
\hline Resubmission & 11 & 11 & 100.0 & \\
\hline
\end{tabular}

The proportion of positive recommendations for those with no 'safety issues' was similar between non-cancer (83\%) and cancer (86\%) DRDs. However, only $40 \%$ of cancer drugs showing no evidence of 'improvements in biomarker/ surrogate outcomes' received a positive recommendation, versus $88 \%$ of non-cancer drugs.

Neither 'daily treatment cost' nor 'ICERs' was associated with recommendation type, but the distribution of recommendations related to these factors appeared to differ between cancer and non-cancer DRDs (Table 3).

After controlling for potential confounders through multiple logistic regressions, only three factors were identified as statistically significantly associated with recommendation type: 1) 'Safety issues', 2) 'Improvement in clinical outcomes', and 3) 'Improvement in patient reported outcomes' (Table 4). In all three, DRDs that did not reported 'safety issues' or showed significantly improved clinical outcomes or patient reported outcomes were more likely to receive a positive listing recommendation. No factors were found to be statistically significantly associated with negative recommendations.

\section{Discussion}

This study examined the potential relationship between factors considered during deliberations by centralized drug review committees in Canada and final recommendation. Cancer drugs were no more or less likely to receive a positive recommendation than those for noncancer. Similarly, no correlation between per patient treatment cost or size of ICER and type of recommendation was found, suggesting that the economic implications of a DRD are not driving deliberations. In contrast, DRDs that offered improvements in clinical outcomes, or PROs were more likely to receive positive recommendations. Similar to our results, two previously published studies of CDR recommendations determined that clinical effectiveness was a strong predictor of recommendation type and there was no association between the size

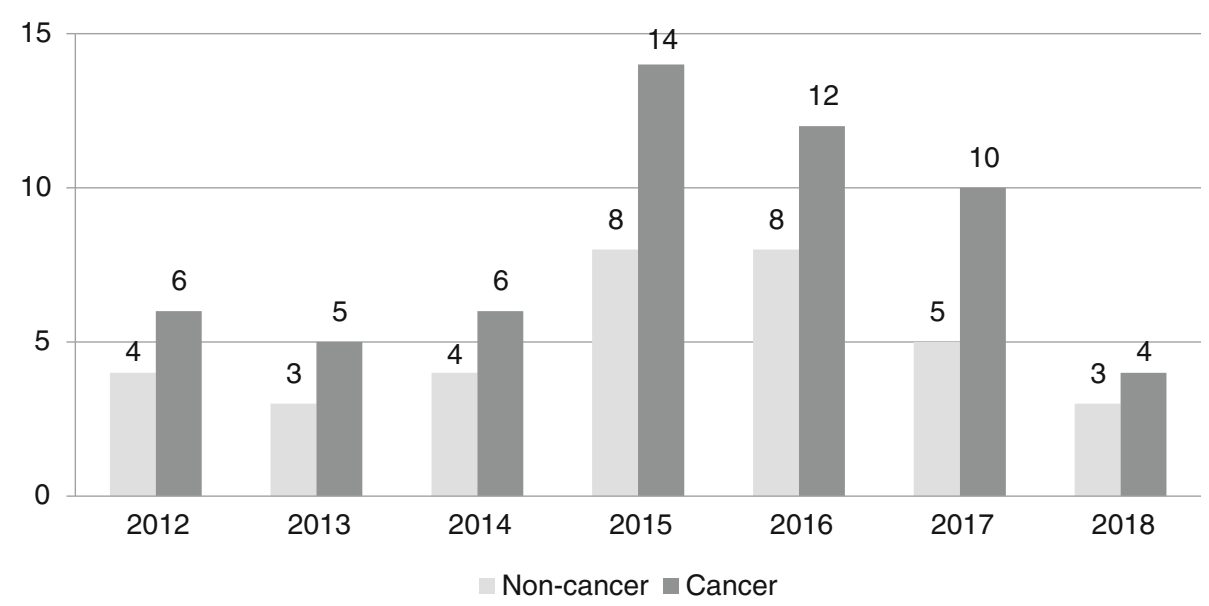

Fig. 2 Distribution of recommendations of new submissions by year of final recommendation 

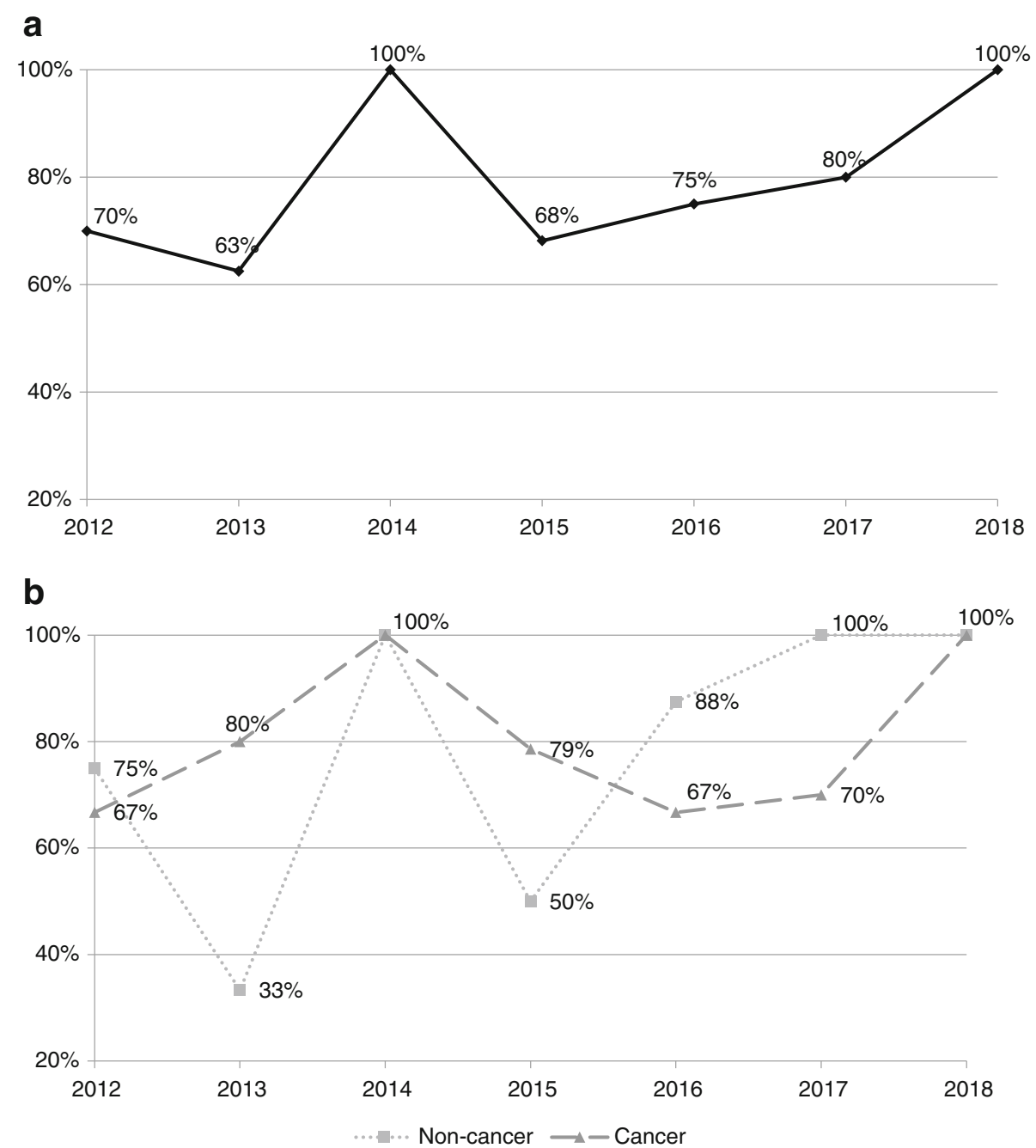

Fig. 3 Percentage of positive recommendations by year of recommendations for: (a) all new submissions and (b) all new submissions stratified by type of condition

of the ICER and recommendation type $[9,10]$. It may be argued that decision makers consider economic models useful when supported by strong clinical evidence [22], which is not usually available for DRDs [23]. In the case of DRDs, other societal considerations such as the principle of social solidarity and the right to health may play a more important role [23, 24].

In recent years, CADTH has made efforts to better align the CDR and PCODR processes [5, 25]. The lack of differences in recommendations based on type of indication suggests that their efforts have been successful. This now raises questions around the need for two review processes. To our knowledge, no other countries with centralized drug reviews have created separate processes for cancer drugs. While previously published studies have found no rationale for the establishment of pCODR [26], it has been argued that while unclear, there may be good reasons [27].
Overall, the proportions of positive recommendations on new submissions were high, although they fluctuated between 2012 and 2015. From 2012 to 2018, two changes in the deliberative framework may have contributed to the increase in positive recommendations. In November 2012, CADTH published a framework for CDR in which price reduction was added as a condition for listing the drug. The framework also included a category of "do not list at submitted price", which before 2012, was a subcategory of the "do not list" category [28]. In March 2016, the wording of recommendations was modified once again and the categories of recommendations were reduced to three: "reimburse", "reimburse with clinical criteria and/ or conditions" and "do not reimburse". A negative recommendation around price no longer appears to exist, and costly drugs or those with unfavourable ICERs can receive a recommendation under the category of "reimburse conditional of 
Table 3 Distribution of positive recommendations for all new submissions of DRDs

\begin{tabular}{|c|c|c|c|c|c|c|c|c|c|c|c|c|}
\hline \multirow[b]{2}{*}{ Factors } & \multicolumn{4}{|c|}{ All new submissions } & \multicolumn{4}{|c|}{ Non-Cancer drugs } & \multicolumn{4}{|c|}{ Cancer drugs } \\
\hline & $n$ & $\begin{array}{l}\text { Positive } \\
\text { recommendations }\end{array}$ & $\begin{array}{l}\% \\
\text { Positive }\end{array}$ & $\begin{array}{l}p^{-} \\
\text {value* }\end{array}$ & n & $\begin{array}{l}\text { Positive } \\
\text { recommendations }\end{array}$ & $\begin{array}{l}\% \\
\text { Positive }\end{array}$ & $\begin{array}{l}p^{-} \\
\text {value* }\end{array}$ & $n$ & $\begin{array}{l}\text { Positive } \\
\text { recommendations }\end{array}$ & $\begin{array}{l}\% \\
\text { Positive }\end{array}$ & $\begin{array}{l}p- \\
\text { value }^{*}\end{array}$ \\
\hline All & 92 & 71 & 77.2 & & 35 & 27 & 77.1 & & 57 & 44 & 77.2 & \\
\hline Type of condition & & & & 0.996 & & & & & & & & \\
\hline Cancer & 57 & 44 & 77.2 & & & & & & & & & \\
\hline Non-cancer & 35 & 27 & 77.1 & & & & & & & & & \\
\hline \multicolumn{13}{|l|}{ Submission characteristics } \\
\hline Presence of RCTs & & & & 0.083 & & & & 0.033 & & & & 0.727 \\
\hline No & 22 & 14 & 63.6 & & 7 & 3 & 42.9 & & 15 & 11 & 73.3 & \\
\hline Yes & 70 & 57 & 81.4 & & 28 & 24 & 85.7 & & 42 & 33 & 78.6 & \\
\hline $\begin{array}{l}\text { Therapeutic class of } \\
\text { drug }\end{array}$ & & & & 0.714 & & & & 0.418 & & NA & & \\
\hline $\begin{array}{l}\text { Alimentary tract \& } \\
\text { metabolism }\end{array}$ & 10 & 9 & 90.0 & & 10 & 9 & 90.0 & & & & & \\
\hline $\begin{array}{l}\text { Antineoplastic \& } \\
\text { immunomodulating }\end{array}$ & 68 & 51 & 75.0 & & 11 & 7 & 63.6 & & & & & \\
\hline Others & 14 & 11 & 78.6 & & 14 & 11 & 78.6 & & & & & \\
\hline \multicolumn{13}{|l|}{ Characteristics of disease } \\
\hline Prevalence & & & & 1.000 & & & & 1.000 & & & & 1.000 \\
\hline Ultra- orphan & 14 & 11 & 78.6 & & 8 & 6 & 75.0 & & 6 & 5 & 83.3 & \\
\hline Orphan & 78 & 60 & 96.9 & & 27 & 21 & 77.8 & & 51 & 39 & 76.5 & \\
\hline Clinical need & & & & 0.051 & & & & 0.419 & & & & 0.070 \\
\hline $\mathrm{No} /$ not stated & 28 & 18 & 64.3 & & 20 & 14 & 70.0 & & 8 & 4 & 50.0 & \\
\hline Yes & 64 & 53 & 82.8 & & 15 & 13 & 86.7 & & 49 & 40 & 81.6 & \\
\hline \multicolumn{13}{|l|}{ Clinical safety/ efficacy } \\
\hline Safety issues & & & & 0.021 & & & & 0.226 & & & & 0.102 \\
\hline Yes & 33 & 21 & 63.6 & & 11 & 7 & 63.6 & & 22 & 14 & 63.6 & \\
\hline No & 59 & 50 & 84.7 & & 24 & 20 & 83.3 & & 35 & 30 & 85.7 & \\
\hline $\begin{array}{l}\text { Improvements in } \\
\text { biomarker/surrogate } \\
\text { outcomes }\end{array}$ & & & & 0.316 & & & & 0.228 & & & & 0.006 \\
\hline $\begin{array}{l}\text { No/ inconsistent/ not } \\
\text { measured }\end{array}$ & 27 & 19 & 70.4 & & 17 & 15 & 88.2 & & 10 & 4 & 40.0 & \\
\hline Yes & 65 & 52 & 80.0 & & 18 & 12 & 66.7 & & 47 & 40 & 85.1 & \\
\hline $\begin{array}{l}\text { Improvements in clinical } \\
\text { outcomes }\end{array}$ & & & & 0.005 & & & & 0.073 & & & & 0.084 \\
\hline $\begin{array}{l}\text { No/ inconsistent/ not } \\
\text { measured }\end{array}$ & 66 & 46 & 69.7 & & 25 & 17 & 68.0 & & 41 & 29 & 70.7 & \\
\hline Yes & 26 & 25 & 96.1 & & 10 & 10 & 100.0 & & 16 & 15 & 93.7 & \\
\hline Improvements in PRO & & & & 0.010 & & & & 0.299 & & & & 0.042 \\
\hline $\begin{array}{l}\text { No/ inconsistent/ not } \\
\text { measured }\end{array}$ & 67 & 47 & 70.1 & & 29 & 21 & 72.4 & & 38 & 26 & 68.4 & \\
\hline Yes & 25 & 24 & 96.0 & & 6 & 6 & 100.0 & & 19 & 18 & 94.7 & \\
\hline \multicolumn{13}{|l|}{ Quality of evidence } \\
\hline $\begin{array}{l}\text { Availability of } \\
\text { comparative data }\end{array}$ & & & & 0.427 & & & & 1.000 & & & & 0.510 \\
\hline No & 33 & 27 & 81.8 & & 14 & 11 & 78.6 & & 19 & 16 & 84.2 & \\
\hline Yes & 59 & 44 & 74.6 & & 21 & 16 & 76.2 & & 38 & 28 & 73.7 & \\
\hline
\end{tabular}


Table 3 Distribution of positive recommendations for all new submissions of DRDs (Continued)

\begin{tabular}{|c|c|c|c|c|c|c|c|c|c|c|c|c|}
\hline \multirow[b]{2}{*}{ Factors } & \multicolumn{4}{|c|}{ All new submissions } & \multicolumn{4}{|c|}{ Non-Cancer drugs } & \multicolumn{4}{|c|}{ Cancer drugs } \\
\hline & $n$ & $\begin{array}{l}\text { Positive } \\
\text { recommendations }\end{array}$ & $\begin{array}{l}\% \\
\text { Positive }\end{array}$ & $\begin{array}{l}p- \\
\text { value* }\end{array}$ & $\mathrm{n}$ & $\begin{array}{l}\text { Positive } \\
\text { recommendations }\end{array}$ & $\begin{array}{l}\% \\
\text { Positive }\end{array}$ & $\begin{array}{l}p- \\
\text { value* }\end{array}$ & $\mathrm{n}$ & $\begin{array}{l}\text { Positive } \\
\text { recommendations }\end{array}$ & $\begin{array}{l}\% \\
\text { Positive }\end{array}$ & $\begin{array}{l}p- \\
\text { value* }^{*}\end{array}$ \\
\hline $\begin{array}{l}\text { Consistency between } \\
\text { population in trials and } \\
\text { indications }\end{array}$ & & & & 0.130 & & & & 0.431 & & & & 0.345 \\
\hline No & 48 & 34 & 70.8 & & 21 & 15 & 71.4 & & 27 & 19 & 70.4 & \\
\hline Yes & 44 & 37 & 84.1 & & 14 & 12 & 85.7 & & 30 & 25 & 83.3 & \\
\hline $\begin{array}{l}\text { Bias in outcome } \\
\text { measures }\end{array}$ & & & & 0.503 & & & & 0.216 & & & & 1.000 \\
\hline Yes & 54 & 43 & 79.6 & & 12 & 11 & 91.7 & & 42 & 32 & 76.2 & \\
\hline No & 38 & 28 & 73.7 & & 23 & 16 & 69.6 & & 15 & 12 & 80.0 & \\
\hline Long term data & & & & 0.186 & & & & 0.390 & & & & 0.346 \\
\hline No & 62 & 45 & 72.6 & & 25 & 18 & 72.0 & & 37 & 27 & 73.0 & \\
\hline Yes & 30 & 26 & 86.7 & & 10 & 9 & 90.0 & & 20 & 17 & 85.0 & \\
\hline $\begin{array}{l}\text { Other study design } \\
\text { issues }\end{array}$ & & & & 0.202 & & & & 1.000 & & & & 0.044 \\
\hline Yes & 58 & 42 & 72.4 & & 19 & 15 & 78.9 & & 39 & 27 & 69.2 & \\
\hline No & 34 & 29 & 85.3 & & 16 & 12 & 75.0 & & 18 & 17 & 94.4 & \\
\hline \multicolumn{13}{|l|}{ Cost/ cost-effectiveness } \\
\hline Daily treatment cost & & & & 1.000 & & & & 0.298 & & & & 0.258 \\
\hline$\leq 150$ & 19 & 15 & 78.9 & & 13 & 12 & 92.3 & & 6 & 3 & 50.0 & \\
\hline $150-500$ & 52 & 40 & 76.9 & & 8 & 5 & 62.5 & & 44 & 35 & 79.6 & \\
\hline$>500$ & 21 & 16 & 76.2 & & 14 & 10 & 71.4 & & 7 & 6 & 85.7 & \\
\hline ICER in \$CDN/QALYs a & & & & 0.647 & & & & 1.000 & & & & 0.194 \\
\hline$\leq 100,000$ & 12 & 11 & 91.7 & & 2 & 2 & 100.0 & & 10 & 9 & 90.0 & \\
\hline $100,000-500,000$ & 48 & 37 & 77.1 & & 7 & 6 & 85.7 & & 41 & 31 & 75.6 & \\
\hline$>500,000$ & 16 & 13 & 81.2 & & 12 & 11 & 91.7 & & 4 & 2 & 50.0 & \\
\hline
\end{tabular}

DRDs Drugs for rare diseases, ICER Incremental cost-effectiveness ratio, NA Not applicable, PRO Patient-reported outcomes, $R C T$ Randomized controlled trial ${ }^{*} p$-values based on Pearson's chi-square statistic or Fisher's exact test

${ }^{a}$ Data on ICER was only available for 76 recommendations

reduced price". Further, this framework provides the option of issuing a positive recommendation in "exceptional cases" in which there are uncertainties around the effectiveness of a drug. "Exceptional cases" may be relevant to rare diseases (i.e., the drug is for life-threatening conditions and/ or affects a small population) [5]. While our data show an increase in positive recommendations since 2016, further research with long-term data is required in order to investigate the impact of these changes in a more robust way.

\section{Limitations}

This study has five main limitations. First, for some recommendations, a judgement call was required in order to classify them as positive or negative. For example, "list if ... substantial reduction in price" may be considered a

Table 4 Results of multiple regression analysis of DRDs

\begin{tabular}{lr}
\hline Variables in the model & OR (95\%Cl) \\
\hline Presence of RCTs (ref:: no) & $2.9(0.7 ; 11.8)$ \\
Safety issues (ref: yes) & $4.0(1.2 ; 13.6)$ \\
Improvements in clinical outcomes (ref: yes) & $20.6(2.2 ; 189.7)$ \\
Improvements in patient reported outcomes (ref: yes) & $12.1(1.3 ; 110.5)$ \\
Consistency between population in trial and indications (ref: no) & $3.5(0.9 ; 12.7)$ \\
\hline
\end{tabular}


negative recommendation because it could ultimately yield a negative reimbursement decision. However, similar to previously published work, we considered a positive recommendation to be one in which manufacturers were able to proceed to the next stage, which was price negotiation and reimbursement [29]. Second, the sample size was small and information on some of the variables was not available. Third, the association between feasibility, one of the factors described in documents emerging from pCODR deliberations, and recommendation type was not evaluated, since similar information was not available for drugs reviewed by the CDR. Nonetheless, adoption feasibility takes into account budget impact, which may be an important consideration during pricing and reimbursement decision-making [30]. Fourth, biomarker and surrogate outcomes were included in the same category due to small sample size. According to the FDA, surrogate outcomes are biomarkers that can predict clinical outcomes $[17,31]$. In the case of DRDs, particularly those for noncancer indications, long-term studies designed to gather information on the natural progression of the disease are lacking. Consequently, there is a reliance on biomarkers as surrogates for clinically meaningful outcomes. Finally, with the exception of obtaining disease prevalence rates from external sources to determine eligibility of the DRD for inclusion in the study, analyses were solely based on information reported in the recommendation documents available on the CADTH website. It was not possible to determine the extent to which these documents provided an accurate reflection of the full deliberative process that took place when formulating these recommendations.

\section{Conclusion}

Whether a new submission is for a cancer drug or for a non-cancer drug does not appear to affect its likelihood of receiving a positive reimbursement recommendation. Safety and clinical effectiveness, not costs, appear to be the key drivers of the type of reimbursement recommendation.

\section{Abbreviations \\ CADTH: Canadian Agency for Drugs and Technologies in Health; CDR: Common Drug Review; DRDs: Drugs for rare diseases; FDA: Food and Drug Administration; ICER: Incremental cost-effectiveness ratio; iJODR: Interim Joint Oncology Drug Review; NA: Not applicable; pCODR: Pan-Canadian Oncology Drug Review; PRO: Patient reported outcomes; RCT: Randomized controlled trial}

\section{Acknowledgements}

Not applicable.

\section{Authors' contributions}

FNIN: contributed substantially to study conception and design, data collection, analysis and interpretation of data, draft and final approval of manuscript. TS: contributed substantially to study conception and design, data collection, analysis and interpretation of data, draft and final approval of manuscript. JS: contributed substantially to analysis and interpretation of data, draft and final approval of manuscript. GJ: contributed substantially to analysis and interpretation of data, draft and final approval of manuscript.
DM: contributed substantially to study conception and design, interpretation of data, draft and final approval of manuscript.

\section{Funding}

Supported by a financial contribution from the Canadian Institutes of Health Research.

\section{Availability of data and materials}

The datasets used and analysed during the current study are available from the corresponding author on reasonable request.

\section{Ethics approval and consent to participate}

Not applicable.

\section{Consent for publication}

Not applicable.

\section{Competing interests}

The authors declare that they have no competing interests.

\section{Author details}

${ }^{1}$ Health Technology \& Policy Unit, School of Public Health, University of Alberta, Edmonton, AB, Canada. ${ }^{2}$ Department of Medicine, University of Calgary, Calgary, AB, Canada. ${ }^{3}$ School of Public Health, University of Alberta, Edmonton, AB, Canada.

Received: 10 April 2019 Accepted: 26 May 2019

Published online: 07 June 2019

\section{References}

1. Hughes DA, Tunnage B, Yeo ST. Drugs for exceptionally rare diseases: do they deserve special status for funding? QJM. 2005; 98(11):829-36.

2. Drummond MF, Wilson DA, Kanavos P, Ubel P, Rovira J. Assessing the economic challenges posed by orphan drugs. Int J Technol Assess Health Care. 2007;23(1):36-42

3. CADTH Common Drug Review (CDR). https://www.cadth.ca/about-cadth/ what-we-do/products-services/cdr. Accessed 1 Apr 2019.

4. About the pan-Canadian Oncology Drug Review (pCODR). https://cadth.ca/ pcodr/about-pcodr. Accessed 1 May 2019.

5. Recommendation Framework for CADTH Common Drug Review and pan_canadian Oncology Drug Review Programs: Guidance for CADTH's Drug Expert Committees. https://www.cadth.ca/media/cdr/templates/ pre-sub-phase/CDR_pCODR_recommendations_framework.pdf. Accessed 1 May 2019.

6. McCormick Jl, Berescu LD, Tadros N. Common drug review recommendations for orphan drugs in Canada: basis of recommendations and comparison with similar reviews in Quebec, Australia, Scotland and New Zealand. Orphanet J Rare Dis. 2018;13(1):27.

7. Rawson NS. Health technology assessment of new drugs for rare disorders in Canada: impact of disease prevalence and cost. Orphanet J Rare Dis. 2017;12(1):59.

8. Chabot I, Rocchi A. Oncology drug health technology assessment recommendations: Canadian versus UK experiences. Clinicoecon Outcomes Res. 2014;6:357-67.

9. Janoudi G, Amegatse W, Mclntosh B, Sehgal C, Richter T. Health technology assessment of drugs for rare diseases: insights, trends, and reasons for negative recommendations from the CADTH common drug review. Orphanet J Rare Dis. 2016;11(1):164.

10. Rocchi A, Miller E, Hopkins RB, Goeree R. Common drug review recommendations: an evidence base for expectations? Pharmacoeconomics. 2012:30(3):229-46.

11. Maguire B, Tilden D. PHP165 - key drivers of Pbac decisions for the reimbursement of orphan drugs on the life saving drugs program. Value Health. 2013;16(7):A480-1.

12. Tordrup D, Tzouma V, Kanavos P. Orphan drug considerations in health technology assessment in eight european countries. Rare Dis Orphan Drugs. 2014;1(3):86-97.

13. Higgins JPT, Green S. Cochrane handbook for systematic reviews of interventions version 5.1.0. Chichester: Wiley-Blackwell; 2011. 
14. Lee DK, Wong B. An orphan drug framework (ODF) for Canada. J Popul Ther Clin Pharmacol. 2014;21(1):e42-6.

15. NICE Citzens Council. Ultra orphan drugs. London: National Institute for Health and Care Excellence (NICE) 2004 Nov 19;Citzens Council Reports no. 4.

16. Orphanet- The portal for rare diseases and orphan drugs. 2019. https:// www.orpha.net/consor/cgi-bin/index.php?Ing=EN. Accessed 1 May 2019

17. FDA-NIH Biomarker Working Group. BEST (Biomarkers, EndpointS, and other Tools). 2-5-2018. Silver Spring, MD; Bethesda, MD, Food and Drug Administration (US); National Institute of Health (US).

18. Hosmer D, Lemeshow S, Sturdivant R. Applied logistic regression. 3rd ed. Hoboken: Wiley; 2013.

19. Bursac Z, Gauss CH, Williams DK, Hosmer DW. Purposeful selection of variables in logistic regression. Source Code Biol Med. 2008;3:17.

20. Hosmer D, Lemeshow S, Kalr K. Goodness-of-fit testing for the logistic regression model when the estimated probabilities are small. Biom J. 1988;30:911-24

21. Hosmer D, Lemeshow S. Goodness-of-fit tests for the multiple logistic regression model. Communications Stastitics. 1980;A9:1043-69.

22. Rocchi A, Menon D, Verma S, Miller E. The role of economic evidence in Canadian oncology reimbursement decision-making: to lambda and beyond. Value Health. 2008;11(4):771-83.

23. Simoens S. Pricing and reimbursement of orphan drugs: the need for more transparency. Orphanet J Rare Dis. 2011;6:42.

24. Dolan P, Shaw R, Tsuchiya A, Williams A. QALY maximisation and people's preferences: a methodological review of the literature. Health Econ. 2005:14(2):197-208.

25. CADTH. Consultation on recommendation framework for CADTH Common Drug Review and pan-Canadian Oncology Drug Review programs. 2018. 2018.

26. McDonald H, Charles C, Elit L, Gafni A. Is there an economic rationale for cancer drugs to have a separate reimbursement review process for resource allocation purposes? Pharmacoeconomics. 2015;33(3):235-41.

27. Hoch JS, Beca J, Sabharwal M, Livingstone SW, Fields AL. Does it matter whether Canada's separate health technology assessment process for Cancer drugs has an economic rationale? Pharmacoeconomics. 2015;33(8):879-82.

28. CADTH. Common Drug Review Recommendations Options and Deliberative Framework. https://www.cadth.ca/sites/default/files/cdr/CADTH-ArchivedUpdates-June2018.pdf. Accessed 3 June 2019.

29. Morgan SG, Thomson PA, Daw JR, Friesen MK. Inter-jurisdictional cooperation on pharmaceutical product listing agreements: views from Canadian provinces. BMC Health Serv Res. 2013;13:34.

30. Skedgel C, Wranik D, Hu M. The relative importance of clinical, economic, patient values and feasibility criteria in Cancer drug reimbursement in Canada: a revealed preferences analysis of recommendations of the pan-Canadian oncology drug review 2011 2017. Pharmacoeconomics. 2018;36(4):467-75.

31. Fleming TR. Surrogate endpoints and FDA's accelerated approval process. Health Aff (Millwood). 2005;24(1):67-78

\section{Publisher's Note}

Springer Nature remains neutral with regard to jurisdictional claims in published maps and institutional affiliations.

Ready to submit your research? Choose BMC and benefit from:

- fast, convenient online submission

- thorough peer review by experienced researchers in your field

- rapid publication on acceptance

- support for research data, including large and complex data types

- gold Open Access which fosters wider collaboration and increased citations

- maximum visibility for your research: over $100 \mathrm{M}$ website views per year

At $\mathrm{BMC}$, research is always in progress.

Learn more biomedcentral.com/submissions 